\title{
Non-destructive analysis of museum objects by fibre-optic Raman spectroscopy
}

\author{
Peter Vandenabeele $\cdot$ Jim Tate $\cdot$ Luc Moens
}

Received: 29 June 2006 / Revised: 8 August 2006 / Accepted: 10 August 2006 / Published online: 5 September 2006

(C) Springer-Verlag 2006

\begin{abstract}
Raman spectroscopy is a versatile technique that has frequently been applied for the investigation of art objects. By using mobile Raman instrumentation it is possible to investigate the artworks without the need for sampling. This work evaluates the use of a dedicated mobile spectrometer for the investigation of a range of museum objects in museums in Scotland, including antique Egyptian sarcophagi, a panel painting, painted surfaces on paper and textile, and the painted lid and soundboard of an early keyboard instrument. The investigations of these artefacts illustrate some analytical challenges that arise when analysing museum objects, including fluorescing varnish layers, ambient sunlight, large dimensions of artefacts and the need to handle fragile objects with care. Analysis of the musical instrument (the Mar virginals) was undertaken in the exhibition gallery, while on display, which meant that interaction with the public and health and safety issues had to be taken into account.
\end{abstract}

Keywords Raman spectroscopy · Conservation science · Art analysis · Non-destructive investigation . Mobile Raman equipment

P. Vandenabeele $(\bowtie) \cdot$ L. Moens

Department of Analytical Chemistry, Ghent University, Proeftuinstraat 86, 9000 Ghent, Belgium

e-mail: peter.vandenabeele@UGent.be

J. Tate

Department of Conservation and Analytical Research, National Museums of Scotland,

Chambers Street,

Edinburgh EH1 1JF, UK

\section{Introduction}

Advances in analytical technology have led to increasing interest in the scientific examination of precious artefacts and antiquities. These examinations may be for a variety of reasons, most commonly fundamental interest in the materials and techniques used by the artist, or understanding their conservation, condition or degradation processes. Analytical data (e.g. from spectroscopic examinations) can, by material identification, assist in dating or authenticating art objects or works of art. The availability of these techniques is therefore very important and it enables us to solve specific questions concerning the conservation, restoration and history of artworks [1-3].

In conservation science, analytical techniques which are non-destructive or micro-destructive are particularly important. Raman spectroscopy is such a technique, allowing material identification from particles down to $1 \mu \mathrm{m}$. This method has already been used for the investigation of different artefacts, including panel paintings [4, 5], glass [6], wall paintings [7, 8], manuscripts [9-11] and historical biomaterials $[12,13]$. Although this technique used to be expensive and highly specialised, it is becoming increasingly more accessible to large museums owing to instrumental improvements and lower costs [14-17]. However, regional museums often still do not have access to this kind of analytical facility. Use of mobile equipment is one solution to this problem, since several institutions may benefit from a single instrument. In addition, mobile fibreoptic-based Raman instrumentation may facilitate the analysis of artefacts that are difficult or impossible to bring to the laboratory, such as wall paintings on the vault of a chapel [8].

In this work we evaluate the use of a mobile fibre-opticbased Raman instrument to perform investigations in a 
museum context. Different types of artefacts were investigated in a variety of locations, testing and demonstrating the flexibility in instrumental set-up. In particular the experimental conditions during the examination of a virginals on exhibition were challenging. Instrument stability after travelling overseas (between Belgium and Edinburgh, UK) was also thoroughly evaluated.

\section{Experimental}

Objects were investigated in the conservation and research laboratories, stores and an exhibition gallery of the National Museums of Scotland (NMS), Edinburgh, as well as in the Burrell Collection (Glasgow) (31 October-13 November 2005). For these surveys mobile Raman equipment was used, which has been described extensively elsewhere [19]. The core of the equipment consists of a SpectraPro-150i $150-\mathrm{mm}$ spectrometer and a thermoelectrically cooled charge-coupled device detector (Roper Scientific/Princeton Instruments). The system is also equipped with a $785-\mathrm{nm}$ diode laser for excitation, which has a maximal output power of $300 \mathrm{~mW}$ at the source. In order to avoid damaging the artefacts during these investigations, and depending on the object and the colour of the area under investigation, the output power was limited to a maximum of $10 \mathrm{~mW}$ (measured at the surface). The accumulation time ranged from $10 \mathrm{~s}$ to $1 \mathrm{~h}$ for weak Raman scatterers. For these investigations the 600 lines/mm grating was selected. Due to non-ideal focussing conditions, the expected minimal laser spot size of ca. $25-\mu \mathrm{m}$ diameter (when working with a $\times 6$ infinity-corrected objective lens) could not be reached. In practice we worked with a larger spot size of ca. $50 \mu \mathrm{m}$. For each area at least 10 spectra were recorded and evaluated in order to tackle paint inhomogeneity at this scale. The experimental configuration was adapted to suit the artefact under study. For example, the probe head could either be mounted horizontally or vertically on the articulating arm and extension tubes could be used on the probe head to facilitate access to the artworks $[8,18]$.

\section{Results and discussion}

When testing the versatility of a mobile spectrometer in a museum context, the technique needs to be applied to a broad range of artefacts and questions. Throughout this text we will provide several examples, illustrating different facets of this approach. Table 1 gives an overview of the investigated artefacts, together with the analytical challenges that these investigations represent.

The examination of Egyptian sarcophagi, both in the National Museums of Scotland (Edinburgh) and in the Burrell Collection (Glasgow Museums \& Art Gallery) illustrate the comparative ease of transportation of the instrument. The capability of the technique to analyse pigments on artefacts covered by a thick varnish layer as well as to undertake the investigation with interference from sunlight are shown. During the examination of a Renaissance painted panel (one of the panels from Dean house, Edinburgh), strong inteference from a fluorescing varnish layer was also encountered. The possibilities of the technique for the non-invasive investigation of fragile artefacts on paper are illustrated by the yellow pigment identification on Indian Kalighat paintings and on a painted textile banner. During the latter survey the articulating arm was used to allow analysis of a large artefact displayed horizontally. Finally, working in the galleries represented an interesting experience as it involved undertaking analytical research whilst taking into account ambient conditions and visitors' curiosity. This approach is illustrated by the study of the Mar virginals.

\section{Pigment analysis of antique Egyptian sarcophagi}

An antique Egyptian sarcophagus [A.1907.569 A], dating from the twenty first/second Dynasty (1069-715 B.C.), was investigated at the NMS by using mobile Raman spectroscopy (Fig. 1a). Samples from this artefact had been examined before by Fourier transform (FT) Raman spectroscopy [19]. The aim of the present study was firstly to investigate whether non-destructive mobile Raman

Table 1 Overview of the different artefacts that were investigated in this work and the analytical challenges they represent

\begin{tabular}{|c|c|}
\hline Investigated artefact & Analytical challenge \\
\hline $\begin{array}{l}\text { Egyptian sarcophagus (NMS) } \\
\text { (A.1907.569A) }\end{array}$ & Pigment identification through a thick varnish layer \\
\hline Egyptian sarcophagus (Glasgow) (1895.167.a) & $\begin{array}{l}\text { Pigment analysis with strong interference from sunlight. Transport to a different museum, } \\
\text { analyse, and return in } 1 \text { day }\end{array}$ \\
\hline Dean panel (H.KL 72) & Analysis of a varnished painting \\
\hline Kalighat painting (A.1912.122) & Analysis of work on paper \\
\hline Indian textile banner (K.2005.234) & Analysis of a textile artefact of large dimensions with a thin and friable painted decoration \\
\hline Mar virginals (H.LT 122) & Investigation in the exhibition gallery open to the public \\
\hline
\end{tabular}




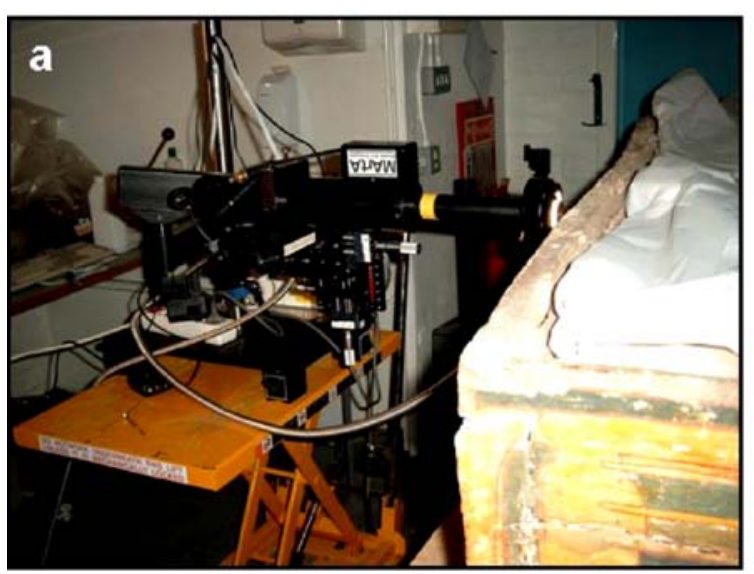

Fig. 1 a Experimental set-up for the investigation of an Egyptian sarcophagus at the NMS. b Stack plot of the baseline-corrected Raman spectrum obtained from the yellow areas of this sarcophagus and the

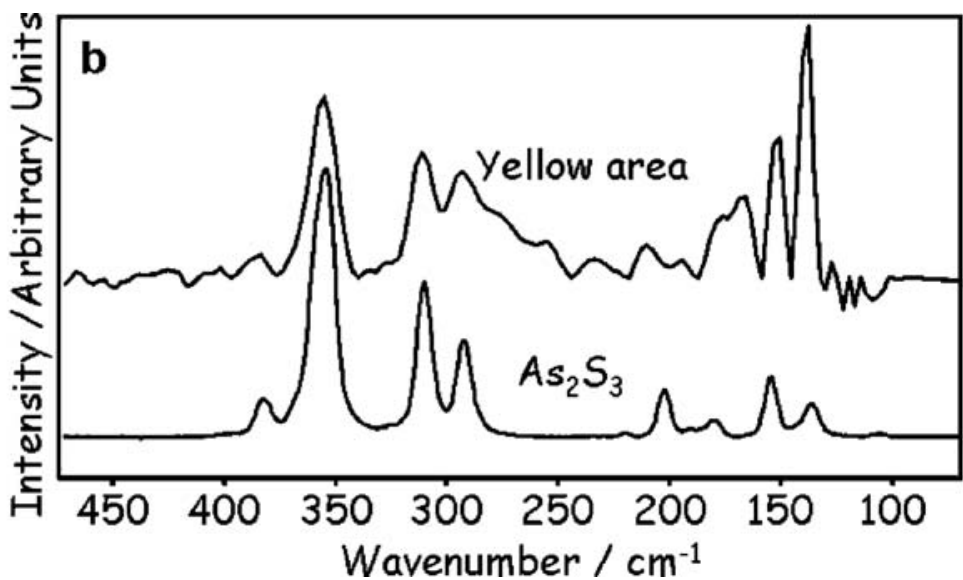

reference spectrum of orpiment $\left(\mathrm{As}_{2} \mathrm{~S}_{3}\right)$. (Experimental conditions for the spectrum of the artefact: 60 accumulations of $1 \mathrm{~s}, \times 6$ objective, $785 \mathrm{~nm}$, ca. $5 \mathrm{~mW}$ at the surface)

agus (Fig. 2a), dating from the ancient Egyptian New Kingdom (1570-1070 B.C.), was in the conservation lab, with high levels of natural light. The conservator wished to know the identity of the yellow pigment on the cover of the sarcophagus, since orpiment $\left(\mathrm{As}_{2} \mathrm{~S}_{3}\right)$ may degrade when exposed to high levels of light. Figure $2 \mathrm{~b}$ shows that the yellow pigment on the sculptured head and hands of the sarcophagus lid indeed was indeed orpiment $\left(\mathrm{As}_{2} \mathrm{~S}_{3}\right)$, whereas the yellow pigment on the other areas was limonite $\left(\mathrm{FeOOH} \cdot n \mathrm{H}_{2} \mathrm{O}\right)$.

Pigment investigation of a painted panel from Dean House, Edinburgh

Mobile Raman spectroscopy was applied to identify the pigments in one of the Renaissance painted panels from Dean House in Edinburgh. The "Deans Panels" are thought to date from around 1627 [20]. The panel representing the sense of hearing (KL 72) is exhibited on a wall, at a height of about $3 \mathrm{~m}$, which would have required the construction of scaffolding in the gallery. Therefore it was considered more practical to remove the panel temporarily from the exhibition and bring it to the conservation lab for analysis. The painted surface was found to be covered with a varnish layer, which contributed to the fluorescence background, although it still was possible to identify the pigments in the investigated areas of the artefact.

Vermilion $(\mathrm{HgS})$ was observed in the red areas, whereas orange areas merely contained red lead $\left(\mathrm{Pb}_{3} \mathrm{O}_{4}\right)$. Brownish red areas were painted with a hematite $\left(\mathrm{Fe}_{2} \mathrm{O}_{3}\right)$-containing paint. On several occasions, mixtures of two of these pigments were encountered. Black areas contained carbon black (C), whereas the white regions were painted by using lead white $\left(2 \mathrm{PbCO}_{3} \cdot \mathrm{Pb}(\mathrm{OH})_{2}\right)$. Pink zones consisted of a mixture of the latter pigment with vermilion; vermilion several collections can share one instrument. The sarcoph- 

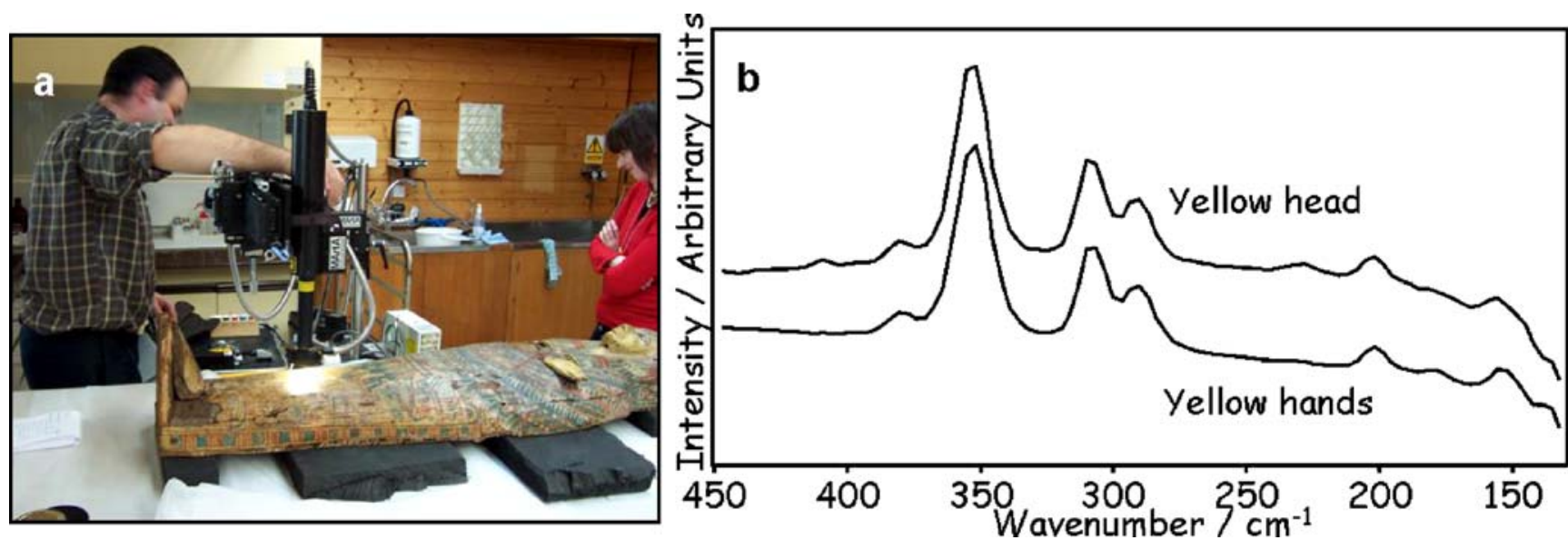

Fig. 2 a Experimental set-up for the investigation of an Egyptian sarcophagus in the conservation lab of the Burrell Collection, Glasgow. Ambient sunlight interfered with the investigations. b Stack

could also be identified in the purple regions (the blue component of which could not be identified). Finally, the yellow areas examined were painted by using lead-tin yellow, type $\mathrm{I}\left(\mathrm{Pb}_{2} \mathrm{SnO}_{4}\right)$. All these pigments are consistent with the early modern origin of the artwork.

Identification of the yellow pigment from an Indian Kalighat painting

The yellow pigment from different areas from an Indian Kalighat painting was examined by using mobile Raman spectroscopy. These are nineteenth century Indian watercolour and opaque media paintings on industrial paper. Since paper artefacts are fragile, special care has to be taken not to damage them during handling and positioning of the spectrometer. Gloves were worn and positioning of the probe head was performed with great care. On all the yellow painted areas of the Kalighat paintings that were examined, the same yellow pigment was encountered. Figure 3 shows

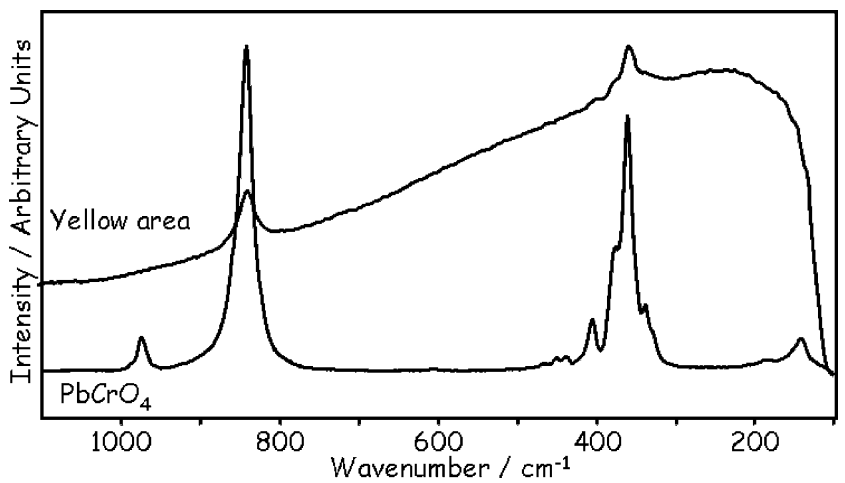

Fig. 3 Stack plot of the Raman spectra obtained from a yellow area from an Indian Kalighat painting and the reference spectrum of chrome yellow $\left(\mathrm{PbCrO}_{4}\right)$. (Experimental conditions for the spectrum of the artefact: 8 accumulations of $150 \mathrm{~s}, \times 6$ objective, $785 \mathrm{~nm}$, ca. $3 \mathrm{~mW}$ at the surface) plot of two Raman spectra obtained from the sculptured head and hands of this sarcophagus. (Experimental conditions: $\times 6$ objective, $785 \mathrm{~nm}$, ca. $5 \mathrm{~mW}$ at the surface, 120 accumulations of $1 \mathrm{~s}$ )

the Raman spectrum obtained, along with the reference spectrum of chrome yellow $\left(\mathrm{PbCrO}_{4}\right)$. It is clear that the yellow pigment in the Kalighat paintings is chrome yellow.

Analysis of a painted banner

The National Museums of Scotland has a large $(1,080 \times 2,030 \mathrm{~mm})$ textile banner of uncertain provenance in its collection. Stylistic interpretations of the polychrome design suggest an Indian origin. The banner depicts, on a green background, colourful imagery of the different stages on the way to heaven (Fig. 4b, detail). Because of its large dimensions and the absence of appropriate non-destructive analytical methods, no previous investigation had been made and little was known of the materials that have been applied. The mobile Raman spectrometer was therefore used to identify the pigments.

In order to be able to examine a range of positions on the surface of the banner, the articulating arm was used for macro-positioning of the probe head, while the artefact was placed horizontally on a table (Fig. 4a). All the paint surfaces were thin, and in several areas the paint was friable or had already been lost. Red areas gave rise to the Raman spectrum of vermilion ( $\mathrm{HgS}$, Fig. $4 \mathrm{~d})$, whereas the orange areas yielded a more complex spectrum, which consists of a combination of massicot $(\mathrm{PbO})$ and red lead $\left(\mathrm{Pb}_{3} \mathrm{O}_{4}\right)$ (Fig. 4c). Red lead is an orange pigment, whereas massicot has a more yellowish shade. It is not clear whether massicot was intentionally added to the paint or whether the latter pigment arose as a side-product of the synthesis of red lead. Other pigments that were positively identified in the banner were calcite $\left(\mathrm{CaCO}_{3}\right)$, carbon black $(\mathrm{C})$, lead white (2 $\left.\mathrm{PbCO}_{3} \cdot 2 \mathrm{H}_{2} \mathrm{O}\right)$, azurite $\left(2 \mathrm{CuCO}_{3} \cdot \mathrm{Cu}(\mathrm{OH})_{2}\right)$ and anatase $\left(\mathrm{TiO}_{2}\right)$. Under the ambient conditions of the conservation laboratory, which did not have full light exclusion, and 
Fig. 4 a Experimental set-up for the investigation of a large textile banner. b Lower part of the investigated textile banner. c Raman spectrum of an orange area of the textile banner, together with the reference spectra of massicot $(\mathrm{PbO})$ and red lead $\left(\mathrm{Pb}_{3} \mathrm{O}_{4}\right)$. (Experimental conditions for the spectrum of the artefact: 1 accumulation of $150 \mathrm{~s}, \times 6$ objective, $785 \mathrm{~nm}$, ca. $10 \mathrm{~mW}$ at the surface). d Raman spectrum of a red area of the textile banner and reference spectrum of vermilion. (Experimental conditions: 1 accumulation of $150 \mathrm{~s}$, $\times 6$ objective, $785 \mathrm{~nm}$, ca. $5 \mathrm{~mW}$ at the surface)
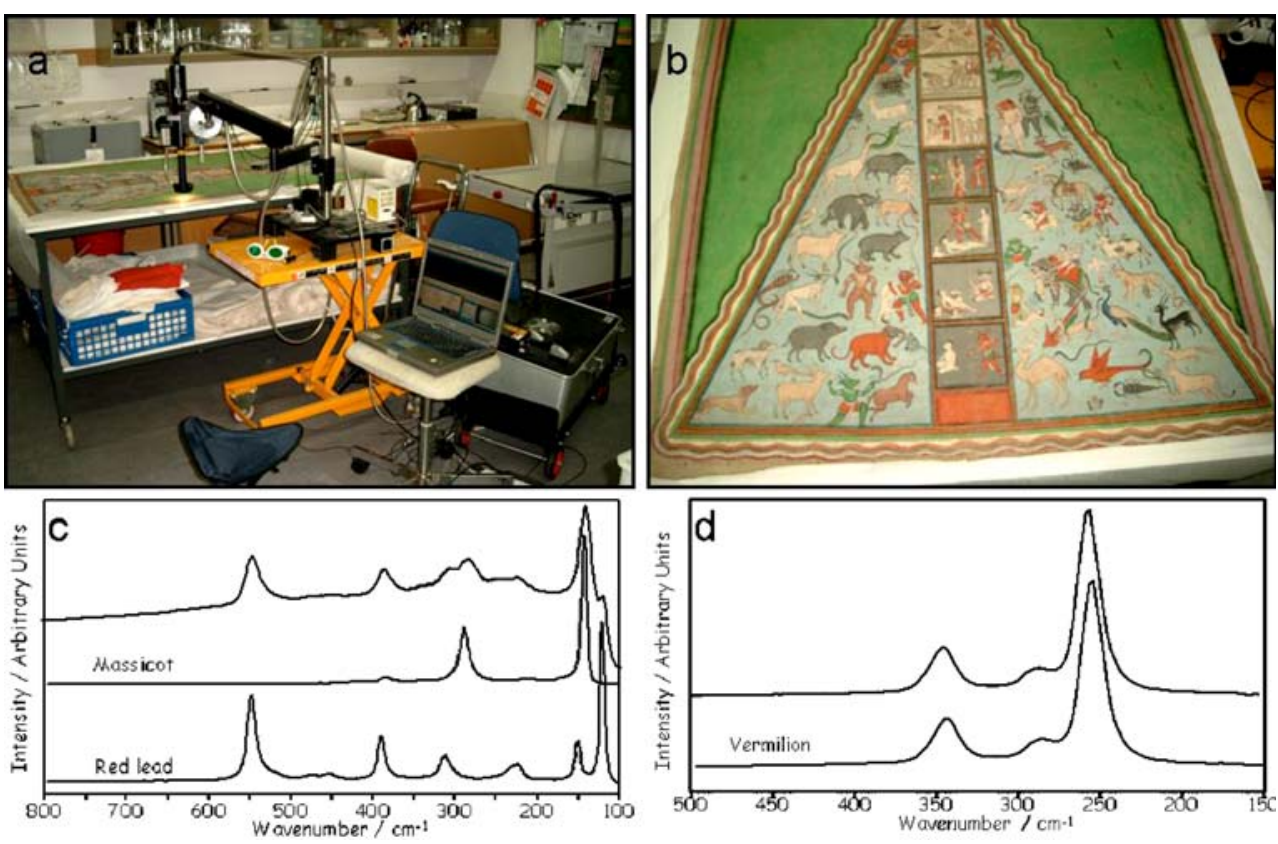

using the 785-nm laser, it was impossible to obtain a spectrum of sufficient quality to identify the green areas on the artefact. One solution to overcome this problem would be to use a Raman instrument with a different laser, with a smaller absorption cross section for the green pigments.

Investigation of an early keyboard instrument, the Mar virginals

The Mar virginals is an early keyboard instrument, which, although probably made in the Low Countries, has a long association with Lady Mary Stewart, countess of Mar and could have been made in Scotland. It probably dates from between A.D. 1560 and 1660, and its lid and soundboard contain three separate painted panels, the central one depicting Orpheus playing to the animals. We wished to compare the paintings on the lid to those on the soundboard, since similar or different pigment compositions may support or disprove the idea that the lid is contemporary to the virginals.
This artefact had to be analysed while on display in the museum gallery, which enabled us to evaluate the feasibility of undertaking the analytical work in a public space. It was necessary to ensure that there were no health and safety risks, especially from direct or scattered light from the laser beam, as well as keeping the electronics and power supply cables and units away from enquiring fingers. The visiting public were clearly intrigued with what was going on and to help explain this, a poster informed the visitors about the experiments.

Working in the gallery also meant that the ambient conditions were far from ideal. During this study, two issues severely hampered the Raman investigations: background light and spatial limitations. It was not possible to reduce the intensity of background light to avoid interference which tended to overwhelm the spectrum, nor on this occasion to undertake the work overnight. And since the Mar virginals was not taken out of its display case, little space was available to align the probe head with the painted surface, the cramped conditions meaning that great care had to be taken not to touch the artefact. To maximise flexibility
Fig. 5 Experimental set-up for the investigation of the Mar virginals
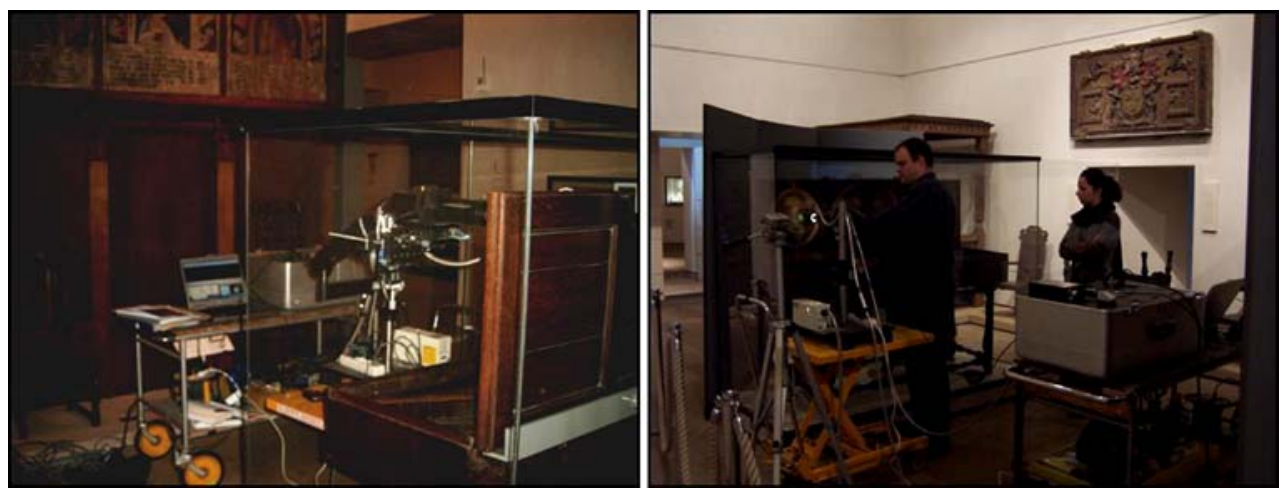
the probe head was mounted on an articulating arm and extension tubes [8] were used to approach the painted surface (Fig. 5).

Nevertheless, despite these non-ideal conditions, the pigments could be identified. White lead $\left(2 \mathrm{PbCO}_{3} \cdot \mathrm{Pb}\right.$ $\left.(\mathrm{OH})_{2}\right)$ is omnipresent: almost all the recorded Raman spectra contain the intense Raman band at $1,056 \mathrm{~cm}^{-1}$, whereas the less intense bands of white lead at 260, 203 and $154 \mathrm{~cm}^{-1}$ are only observed in a few spectra. Apparently, this pigment was applied to modify the hue of the coloured areas, making them appear brighter. From the intense Raman bands at 254, 283 and $343 \mathrm{~cm}^{-1}$, it is clear that the red areas were painted with the red pigment vermilion $(\mathrm{HgS})$, whereas the bright yellow areas were painted by using orpiment $\left(\mathrm{As}_{2} \mathrm{~S}_{3}\right)$. Carbon black (C) is the black pigment which was used in the painted decoration.

In general, the blue areas of the painting did not yield Raman spectra of sufficient quality to allow identification. The reasons for this are multiple. In general, blue and green pigments absorb the red $(785 \mathrm{~nm})$ laser light which hinders the recording of a spectrum. In addition there was a large amount of background radiation, both from the gallery lights and from fluorescence, which was probably caused by the varnish layer. It is very likely that the blue pigment azurite $\left(2 \mathrm{CuCO}_{3} \cdot \mathrm{Cu}(\mathrm{OH})_{2}\right)$ is used in the artwork, since this pigment was very commonly used in Renaissance period: however, unfortunately azurite happens to be a weak Raman scatterer when using a 785-nm laser, which means that small amounts of background radiation easily overwhelm the Raman spectrum.

Although only a few areas on the soundboard could be examined, the pigments on the lid were in good agreement with those on the soundboard. Despite the fact that this research project should be considered as a pilot study, this tends to support the thesis that the lid and the soundboard originate from the same instrument, or at least were painted at a similar period. However other approaches, such as stylistic studies, or taking samples to matching the sporeelement compositions of the paint from the lid and the soundboard [9], are needed to be more definite. Since the investigation of this rare musical instrument was performed in one day, time was confined and only a limited number of areas could be examined. In fact, except for the absence of lead-tin yellow, none of the pigments were rare for an artwork of this period.

\section{Conclusions}

This work reports on the application of mobile Raman spectroscopy to the non-invasive investigation of a range of object of arts in a museum context. The different cases presented here illustrate different obstacles and analytical challenges that are often encountered during direct Raman investigations of museum objects. The investigation of two antique Egyptian sarcophagi shows the possibilities of the technique to deal with artefacts covered by a thick varnish layer as well as the investigation with the interference of ambient sunlight in the conservation laboratory. The investigation of the Dean House panel illustrates the possibilities of pigment investigation although a fluorescing varnish layer is present; the suitability of the method to analyse fragile artefacts was demonstrated by the investigation of Indian Kalighat paintings on paper; the textile banner was both fragile and large. Finally, the Mar virginals has been examined for the first time directly in the exhibition gallery with normal lighting conditions and with visitors present. All these examples illustrate that nondestructive, mobile Raman spectroscopy is able to cover a broad field of research questions on artistic and historical objects, in a range of different experimental conditions, encountered in a museum context.

Acknowledgements The authors are grateful to COST G8 (action 'Non-destructive Analysis and Testing of Museum Objects') for financial support of this short-term scientific mission to the National Museums of Scotland. The mobile equipment was developed with financial support of the Flemish Government (Department of Culture, section 'museumdecreet') and of Ghent University. The authors thank the Research Foundation-Flanders (F.W.O.-Vlaanderen) for its financial support. P.V. wishes as well to acknowledge this Research Foundation (FWO-Vlaanderen) for his postdoctoral grant. Finally, P.V. and J.T. address their gratitude to colleagues in the National Museums of Scotland, particularly Lore Troalen, and also Lynn McClean, Lisa Cumming, Bill Manley, Anita Quye and Ulrike Al-Khamis for their assistance and enthusiasm during this research project, and to Rob Lewis and colleagues at the Burrell Collection, Glasgow.

\section{References}

1. Ciliberto E, Spoto G (eds) (2000) Modern analytical methods in art and archaeology. Chemical snalysis Series, vol 155 . Wiley, New York

2. Edwards HGM, Chalmers JM (eds) (2005) Raman spectroscopy in archaeology and art history, RSC analytical spectroscopy monographs, Royal Society of Chemistry, Cambridge

3. Vandenabeele P (2004) J Raman Spectrosc 35(8-9):607-609 (special issue)

4. Ortega-Aviles M, Vandenabeele P, Tenorio D, Murillo G, JimenezReyes M, Gutierrez N (2005) Anal Chim Acta 550(1-2):164-172

5. Vandenabeele P, Verpoort F, Moens L (2001) J Raman Spectrosc 32(4):263-269

6. Robinet L, Eremin K, del Arco BC, Gibson LT (2004) J Raman Spectrosc 35(8-9):662-670

7. Edwards HGM (2003) J Mol Struct 661:271-277

8. Vandenabeele P, Lambert K, Matthys S, Schudel W, Bergmans A, Moens L (2005) Anal Bioanal Chem 383(4):707-712

9. Vandenabeele P, Wehling B, Moens L, Dekeyzer B, Cardon B, von Bohlen A, Klockenkämper R (1999) Analyst 124(2):169-172

10. Gilbert B, Denoel S, Weber G, Allart D (2003) Analyst 128 (10):1213-1217 
11. Edwards HGM, Farwell DW, Perez FR, Garcia JM (2001) Analyst 126(3):383-388

12. Vandenabeele P, Wehling B, Moens L, Edwards H, De Reu M, Van Hooydonk G (2000) Anal Chim Acta 407(1-2): 261-274

13. Edwards HGM, Hunt DE, Sibley MG (1998) Spectrochim Acta A 54(5):745-757

14. Ambers J (2004) J Raman Spectrosc 35 (8-9):768-773

15. Pages-Camagna S, Calligaro T (2004) J Raman Spectrosc 35(8-9): 633-639

16. Trentelman K, Stodulski L, Pavlosky M (1996) Anal Chem 68 (10):1755-1761
17. Chen K, Leona M, Vo-Dinh KC, Yan F, Wabuyele MB, Vo-Dinh T (2006) J Raman Spectrosc 37(4):520-527

18. Vandenabeele P, Weis TL, Grant ER, Moens LJ (2004) Anal Bioanal Chem 379(1):137-142

19. Eremin K, Quye A, Edwards H, Villar SJ, Manley B (2004) In: Cleland L, Stears K, Davies G (eds) Colours in the ancient Mediterranean world. Colours of ancient Egyptian funerary artefacts in the National Museums of Scotland, BAR International Series 1267:1-8

20. Bath M (2003) Renaissance decorative painting in Scotland. National Museums of Scotland Publishing, Edinburgh, pp 241-242 \& illustration $\mathrm{p} 203$ 